Vol. 20 (2016), pp. 479-485

ISSNe: 2530-6324 || ISSN: 1138-039X

DOI: https://doi.org/10.17979/afdudc.2016.20.0.1960

\title{
EL WHATSAPP COMO MEDIO DE PRUEBA EN EL PROCESO LABORAL. A PROPÓSITO DE UNA SENTENCIA DEL TRIBUNAL SUPERIOR DE JUSTICIA DE GALICIA DE 28 DE ENERO DE 2016
}

\author{
LARA M. MuNÍN SÁNCHEZ \\ Juez sustituta \\ Doctora en Derecho (acreditada como PCD) \\ Profesora Asociada de la Facultad de Ciencias del Trabajo (UDC)
}

Fecha de recepción: 30.6.2016

Fecha de aceptación: 28.7.2016

1. En la Sentencia de la Sala de lo Social del Tribunal Superior de Justicia de Galicia, que se va a analizar y que lleva por fecha el 28 de enero de 2016 -Recurso de Suplicación núm. $4577 / 2015-^{1}$ se procede a analizar, entre otros muchos aspectos, la posibilidad de que un determinado elemento contenido en un hilo de un chat de la aplicación de mensajería automática WhatsApp pueda utilizarse como medio de prueba, fijándose los pasos necesarios para que pueda tener lugar, dada la diferencia existente entre un simple documento y lo que se podría calificar, en los términos del artículo 3.35 del Reglamento (UE) núm. 910/2014 del Parlamento Europeo y del Consejo de 23 de julio de 2014 relativo a la identificación electrónica y los servicios de confianza para las transacciones electrónicas en el mercado interior y por el que se deroga la Directiva 1999/93/CE-, como «contenido almacenado en formato electrónico, en particular, texto o registro sonoro, visual o audiovisual».

La cuestión central (el acceso de un mensaje de WhatsApp al proceso laboral) se ve jalonada por dos consideraciones previas: una, sobre la modificación de los hechos probados y los requisitos para proceder a hacerlo en segunda instancia social (al hilo de la cual se expresa la distinción entre verdad formal y material a los fines del proceso laboral); y otra, acerca de la ficta confessio, que viene a corroborar su libre apreciación por parte del órgano juzgador, al rechazar su aplicación automática ante la incomparecencia de la empresa demandada al acto del juicio.

\footnotetext{
${ }^{1}$ Accesible en el link: http://www.poderjudicial.es.
} 
En realidad y sobre este último aspecto, la dicción del artículo 91.2 de la Ley Reguladora de la Jurisdicción Social ${ }^{2}$, que norma: «Si el llamado al interrogatorio no compareciese sin justa causa a la primera citación, rehusase declarar o persistiese en no responder afirmativa o negativamente, a pesar del apercibimiento que se le haya hecho, podrán considerarse reconocidos como ciertos en la sentencia los hechos a que se refieran las preguntas, siempre que el interrogado hubiese intervenido en ellos personalmente y su fijación como ciertos le resultare perjudicial en todo o en parte»; esa dicción literal ${ }^{3}$-repito- otorga al Juzgador la facultad de tener por confesa a la parte que llamada a declarar no compareciese sin concurrir causa legal, ahora bien, esta posibilidad valorativa no es de ninguna manera una obligación, sino que será su razonable criterio el que determine su recurso o no, de tal forma que implicará -como se ha declarado por la jurisprudencia desde antiguo - que esa decisión no es susceptible de ser fiscalizada por el cauce de un recurso extraordinario como el de Suplicación. De hecho, la facultad jurisdiccional de aplicar la ficta confessio es sistemáticamente reclamada por la parte actora cuando no comparece a juicio la demandada, pero como se ha indicado y el mismo Tribunal Constitucional ${ }^{5}$, se ha encargado de remarcar, en tanto que constituye una forma de valorar la prueba, que ello es de competencia exclusiva de los Tribunales ordinarios. A pesar de ello, el Alto Tribunal no tiene reparos en relacionar directamente la posibilidad reconocida al juez de instancia, si bien en la materia concreta sobre la que versa el procedimiento, con el principio de tutela efectiva y con el derecho al proceso con todas las garantías ${ }^{6}$; en sus propias palabras: «La cuestión litigiosa que se dirime en el presente recurso de amparo es la de si vulnera el derecho a una tutela judicial efectiva sin indefensión (art. 24.1 CE) y a un proceso con todas las garantías y con igualdad de armas (art. 24.2 CE) una resolución judicial que deniega la aplicación de la "ficta confessio"...». «De esta forma, lo que el Tribunal Constitucional hace es extraer consecuencias jurídicas de la negativa de la Administración -o falta de justificación sobre los motivos de la negativa- a presentar los documentos que acreditan unos determinados hechos, y que son los fundamentales para prosperar las pretensiones de la parte demandante, y estas consecuencias no son otras que estimar probado lo alegado por dicha parte actora en relación con sus afirmaciones» ${ }^{7}$.

\footnotetext{
${ }^{2}$ Ley 36/2011, de 10 de octubre, reguladora de la jurisdicción social.

${ }^{3}$ Como sus precedentes artículos 91.2 de la Ley de Procedimiento Laboral de 1995 (Real Decreto Legislativo 2/1995, de 7 de abril, por el que se aprueba el Texto Refundido de la Ley de Procedimiento Laboral), el 91.2 de la Ley de Procedimiento Laboral de 1990 (Real Decreto Legislativo 521/1990, de 27 de abril) y el 81 de la Ley de Procedimiento Laboral de 1980 (Real Decreto Legislativo 1568/1980, de 13 de junio); todos ellos, con unas redacciones casi idénticas.

${ }^{4}$ Véanse las Sentencias del Tribunal Supremo de 11 de febrero de 1972 -Repertorio de jurisprudencia Aranzadi núm. 1972/494-; de 26 de febrero de 1976 -Repertorio de jurisprudencia Aranzadi núm. 1976/755-; de 6 de noviembre de 1985 -Repertorio de jurisprudencia Aranzadi núm. 1985/5727-; de 5 de marzo de 1987 -Repertorio de jurisprudencia Aranzadi núm. 1987/1337-; de 30 de marzo de 1987 Ar. 1758-; de 2 de noviembre de 1987 -Repertorio de jurisprudencia Aranzadi núm. 1987/7779-; y de 9 de junio de 1988 -Repertorio de jurisprudencia Aranzadi núm. 1988/5263-.

${ }_{5}^{5}$ Véase la Sentencia del Tribunal Constitucional núm. 227/1991, de 28 de noviembre.

${ }^{6}$ Cfr. GONZÁLEZ DE LA RIVERA SERRA, X., «Aplicación de la "ficta confessio" en relación con el artículo 24 de la Constitución», Aranzadi Social, núm. 6, 2002, consultado a través de la base de datos Westlaw (BIB 2002/814).

${ }^{7}$ Véase GONZÁLEZ DE LA RIVERA SERRA, X., «Aplicación de la "ficta confessio" en relación con el artículo 24 de la Constitución», cit.
} 
En cuanto al primer aspecto, el referido a la modificación de los hechos probados y los requisitos para proceder a hacerlo en segunda instancia social, la variación pretendida por el trabajador que vio desestimada su demanda no tuvo encaje, de entrada, por la discrecionalidad en el empleo de la ya referida ficta confessio (a la que ya he hecho referencia); y, después, bien por la proscripción de determinados medios de prueba en el recurso de suplicación, en concreto, los de confesión y la testifical $^{8}$; bien porque el documento que cita el recurrente no refleja o no desprende lo que pretende añadir en el relato histórico de la Sentencia, no siendo -dice la resolución«literosuficiente», esto es, carece de poder demostrativo directo, que sí lo tienen aquellos documentos que no precisan de la adición de ninguna otra prueba ni tener que recurrir a conjeturas o complejas argumentaciones, para lograr convencer al Juzgador sobre su realidad. El último de los argumentos -al que ya me he referido- es el rechazo de las modificaciones amparadas en las conversaciones de WhatsApp, porque el propio Magistrado a quo ya había dudado de su veracidad -más bien negado-, es decir, el Juzgador de Instancia consideraba que existía una discrepancia entre lo reflejado en el pantallazo del servicio de mensajería instantáneo y la realidad, lo que implica que después en segunda Instancia- no pueda modificarse dicha apreciación, porque - de lo que se trata- es de la sana crítica, «que podemos decir, siguiendo a MORÓN PALOMINO, que "constituyen juicios generales que han sido elaborados sobre la observación de lo que acontece comúnmente en la realidad de la vida", de tal modo que "todo juicio opuesto a una máxima de esta naturaleza, en cuanto la máxima resulte integrada en una norma jurídica, requiere su rectificación. Resolver sin tenerla en cuenta significa la vulneración de la norma receptora; por lo cual aunque inicialmente la máxima aparezca como una cuestión de hecho, de ninguna manera debe ser sustraída al control del tribunal de casación. Como acertadamente pone de relieve SERRA DOMÍNGUEZ, el motivo se fundará no tanto en la infracción de la máxima como en la del precepto legal que la recoja”. Apunta, finalmente, este autor, con gran sentido común, que además de los sistemas de prueba libre y prueba tasada, existe un tercero intermedio, que sería al que se sujetaría la mayor parte de la prueba en la LECiv del 2000 (así como en la de 1881), en el cual el juzgador no se halla vinculado por la ley a la hora de valorar el medio de prueba (como ocurre en los arts. 319 y 326, supuestos de prueba legal), pero tampoco goza de libertad absoluta (como ocurre en el caso del art. 319.3, que reitera la norma del antiguo art. 2 de la Ley Azcárate, caso de prueba libre), sino que el tribunal de instancia puede valorar libremente la prueba pero siempre dentro de los márgenes de la discrecionalidad, esto es, sin incurrir en arbitrariedad, que es lo que pretende impedir la sujeción a las reglas de la sana crítica» ${ }^{9}$.

En palabras de la Sentencia que se comenta, «no puede invocarse como prueba desvirtuadora de la afirmación o creencia judicial $-o$ en su caso del fraude- la constituida por los documentos cuya desconexión con la realidad acreditada se declara explícita o implícitamente- la Sentencia de Instancia. Tales documentos tan sólo resultan acreditativos del aspecto formal de la cuestión, constituyendo -justamente por

\footnotetext{
${ }^{8}$ Así se proclama en el artículo 193.b) de la Ley Reguladora de la Jurisdicción Social al afirmar que «El recurso de suplicación tendrá por objeto: [...] b) Revisar los hechos declarados probados, a la vista de las pruebas documentales y periciales practicadas»; y se ha fijado desde antiguo, por ejemplo, en las Sentencias del Tribunal Supremo de 24 de junio de 2008 -Recurso de casación ordinaria núm. 128/2007-; y de 18 de junio de 2013 -Repertorio de jurisprudencia Aranzadi núm. 2013/6102-;

${ }_{9}^{9}$ Véase VÁZQUEZ DÍAZ, X., «Modificación en suplicación de los hechos probados fuera de los estrictos cauces del art. 191 b) de la Ley de Procedimiento Laboral: en especial, el error de derecho en la valoración de la prueba y las reglas de la sana crítica», Aranzadi Social, núm. 4, 2002, consultado a través de la base de datos Westlaw (BIB 2002/532).
} 
ello- el presupuesto de la discordancia declarada probada, sin que -por lo mismopuedan en forma alguna ser considerados como demostrativos de que no existe la realidad contraria -o fraudulenta, en su caso- que tiene por acreditada el Magistrado» ${ }^{10}$. En otras palabras, si el Magistrado a quo ha llegado al convencimiento de que el medio de prueba no refleja la realidad y rechaza su virtualidad, no puede posteriormente asumirse como creíble por el tribunal de suplicación, habida cuenta que «el Magistrado de Instancia apura el razonamiento y valora que su contenido no es revelador de ningún despido», por lo que niega que el hilo del chat $^{11}$ demuestre que tuviese lugar, refiriéndose a que el medio de prueba estrella -el pantallazo de un mensaje- acreditase el cese del actor y, con ello, su relación laboral y, lo que es más importante, la fecha del despido.

2. En todo caso, antes de proceder al análisis de esta resolución es preciso enmarcarla, siquiera los hechos son muy escuetos, debido a que el Magistrado de Instancia no tuvo por probados ninguno de los elementos que pretendía hacer constar el actor, $y$, después, éste fracasa -como se ha indicado antes- en su intento de modificar dicho marco fáctico. Sus hechos declarados probados -relevantes- son: uno, el actor prestó servicios desde una fecha indeterminada hasta otra, también indeterminada, para una empresa dedicada a actividades subacuáticas y buceo; dos, el demandante se dedicaba a la atención y asistencia a usuarios de la empresa, recarga de botellas de aire y mantenimiento de la instalación; tres, por Sentencia del Juzgado de lo Social núm. Cuatro de los de Vigo de 5 de agosto de 2015 se desestimó su demanda de despido; cuatro, interpuesto recurso de suplicación por la parte actora, se dictó la Sentencia del Tribunal Superior de Justicia de Galicia de 28 de enero de 2016 -número de Recurso de Suplicación 4577/2015-, que desestimó el recurso y confirmó la Sentencia de Instancia; y cinco, esta Sentencia es ya firme y que -hasta donde conozco- resuelve por primera vez en el ámbito laboral -al menos en Suplicación- la cuestión de cómo se incorporan los mensajes de WhatsApp al proceso para poder emplearlos como prueba.

3. La resolución comienza, entrando ya en el meollo de cuestión que nos interesa, mediante un argumento que asume a mayor abundamiento, conforme a la técnica del obiter dictum -o, en plural, obiter dicta-, que significa dicho de paso y que se emplea muy frecuentemente en las Sentencias del Tribunal Supremo o de otros Tribunales Superiores para afinar un determinado tema que prevén que se puede plantear con posterioridad o que el Tribunal entiende que debe aclarar, siquiera no se trate del que constituye el thema decideni o cuestión de fondo a resolver, que en este asunto -en realidad- era un hipotético despido producido en una determinada fecha a través de un mensaje de WhatsApp; lo que ocurre es que se considera importante especificar cuáles son los requisitos para que un medio de prueba -relativamente novedoso- pudiese apreciarse por el Juzgador correspondiente. En sus propias palabras, «para considerar una conversación de WhatsApp como documento -a los fines del proceso laboral-, sería preciso que se hubiese aportado no sólo la copia en papel de la impresión de pantalla o, como se denomina usualmente, "pantallazo" -que es lo único

\footnotetext{
${ }^{10}$ Fundamento Jurídico Segundo, (a).

${ }^{11}$ Se conoce como chat la charla o conversación escrita y realizada de manera instantánea mediante el uso de un software entre dos o más personas conectadas a la red, generalmente Internet, ya sea a través de los llamados chats públicos (si cualquier persona puede entrar), o privados (cuando la entrada está sujeta a autorización).
} 
se cumple por el actor-, sino una transcripción de la conversación y la comprobación de que de que ésta se corresponde con el teléfono y con el número correspondientes»» ${ }^{12}$. Se habla de «pantallazo" o, en su término inglés, screenshot para referirse a la captura de la imagen del mensaje, esto es, una imagen tomada por una computadora o un teléfono inteligente para capturar los elementos vistos en la pantalla del monitor $\mathrm{u}$ otro dispositivo de salida visual.

Lo que es indudable que los mensajes (ya únicos, ya cruzados como una conversación) son medios de prueba, que podrían equipararse a la documental, puesto que la Ley 59/2003, de 19 de diciembre, de firma electrónica, establece en su artículo 3.5 , que «[s]e considera documento electrónico la información de cualquier naturaleza en forma electrónica, archivada en un soporte electrónico según un formato determinado $\mathrm{y}$ susceptible de identificación y tratamiento diferenciado»; $\mathrm{y}$, además, que «[e]1 documento electrónico será soporte de: [...] c) Documentos privados» [artículo 3.6.c) de la Ley citada] -que es donde se encuadraría un mensaje de WhatsApp, pues no deja de ser un «contenido almacenado en formato electrónico, en particular, texto o registro sonoro, visual o audiovisual» -como expresa el artículo 3.35 del Reglamento (UE) núm. 910/2014 del Parlamento Europeo y del Consejo de 23 de julio de 2014 relativo a la identificación electrónica y los servicios de confianza para las transacciones electrónicas en el mercado interior y por el que se deroga la Directiva 1999/93/CE-, vinculado a un número de teléfono y a una $\operatorname{IMEI}^{13}$, lo que facilita su identificación. Todo lo cual se complementa con la dicción del artículo 3.7 de la misma Ley que añade que «[1]os documentos a que se refiere el apartado anterior tendrán el valor y la eficacia jurídica que corresponda a su respectiva naturaleza, de conformidad con la legislación que les resulte aplicable»; lo que ya nos introduce en el tema del WhatsApp como medio de prueba y su consideración como documento, permitiendo fijar las condiciones en las que se puede aportar al proceso. De hecho, en la Sentencia se menciona que su condición de prueba es tan indiscutible que ya tiene plasmación normativa, en Convenios Colectivos, recogiéndose dos ejemplos: uno, el artículo 24 del Convenio Colectivo del sector de Industrias de Aderezo, Relleno, Envasado y Exportación de Aceituna de Sevilla ${ }^{14}$ fija que «[1] as llamadas al trabajo se podrán realizar por cualquier medio admitido en derecho y en cualquier caso siempre mediante su publicación en el tablón de anuncios. A modo meramente enunciativo serán válidos los llamamientos realizados por teléfono, SMS, o WhatsApp o email»; y, otro, el artículo 30.n) del Convenio Colectivo Provincial para el sector de Oficinas y Despachos de la provincia de Zamora ${ }^{15}$ prohíbe la utilización de «WhatsApp durante la jornada laboral, bien desde el móvil personal o móvil de la empresa», configurando dicho uso como falta grave, sancionable.

A continuación se fijan -en lo que es más novedoso- los requisitos que deberían cumplir los referidos mensajes para poder ser considerados como propios medios de prueba y aportarse válidamente al proceso; y se hace en los siguientes términos: «Apurando nuestras consideraciones sobre la prueba de mensajería instantánea y con fines esclarecedores, para que aceptemos como documento una conversación o mensaje

\footnotetext{
${ }^{12}$ Son palabras del Fundamento Jurídico Cuarto, número dos de la Sentencia analizada.

${ }^{13}$ De las siglas International Mobile Station Equipment Identity (identidad internacional de equipo móvil) es un código USSD pregrabado en los teléfonos móviles GSM. Este código identifica al aparato de forma exclusiva a nivel mundial, y es transmitido por el aparato a la red al conectarse a esta.

${ }^{14}$ Publicado en el Diario Oficial de la Provincia de Sevilla el 12 de junio de 2014.

${ }^{15}$ Publicado en el Diario Oficial de la Provincia de Zamora 2 de mayo de 2014).
} 
de este tipo (algo diferente a su valor probatorio) podríamos establecer cuatro supuestos: (a) cuando la parte interlocutora de la conversación no impugna la conversación; (b) cuando reconoce expresamente dicha conversación y su contenido; (c) cuando se compruebe su realidad mediante el cotejo con el otro terminal implicado (exhibición); o, finalmente, (d) cuando se practique una prueba pericial que acredite la autenticidad y envío de la conversación, para un supuesto diferente de los anteriores»; sin desdeñar los riesgos de manipulación existentes. Esto último no es tan improbable como pueda llegar a pensarse, incluso, aunque se practique una prueba pericial, habida cuenta que la manipulación del mensaje o del chat es relativamente sencilla ${ }^{16}$, porque existen aplicaciones (WhatsApp Toolbox, Fake SMS Sender, SQlite Editor y un largo etcéter ${ }^{17}$ ), que permiten crear inexistentes mensajes de texto, editar los recibidos o simular el envío y recepción de $\mathrm{SMS}^{18}$, alterando la hora de edición o de recepción, en su caso. La propia Asociación de Internautas ${ }^{19}$ alerta sobre la existencia de dichas aplicaciones, que pueden ser fácilmente utilizadas -incluso- por personas no expertas en informática; y, lo más grave, es que estas técnicas manipuladoras son capaces de burlar cualquier análisis forense informático.

En todo caso, lo importante es que en la resolución se han fijado los pasos para que un mensaje de WhatsApp acceda al proceso: uno, que la otra parte no niegue o no impugne el contenido del mensaje, en cuyo caso, bastará la impresión del pantallazo; dos, en caso de negativa, será preciso la comprobación de ambos terminales, para cotejarlos y descubrir si lo reflejado en uno y otro coincide y se puede concluir la realidad del mensaje; y, finalmente, si no fuese posible actuar de la manera anterior (no aparece uno de los terminales o el titular se niega a entregarlo), sería preciso acudir a la pericial informática -con el posible riesgo ya apuntado-.

4. Como colofón a lo expuesto, creo que la opinión que podría verterse sobre esta Sentencia del Tribunal Superior de Justicia de Galicia de 28 de enero de 2016 número de Recurso de Suplicación 4577/2015- es muy positiva, porque no sólo se trata de una resolución innovadora ${ }^{20}$, al menos, en lo que se refiere a expresar los requisitos que ha de cumplir un «contenido almacenado en formato electrónico, en particular, texto o registro sonoro, visual o audiovisual» -en este caso, un mensaje de WhatsApppara que tenga acceso al procedimiento, sino también didáctica, en el sentido que, pese a denegar el recurso presentado, realiza un pronunciamiento obiter dicta para poder incorporar aquéllos a los fines de futuros recursos -y motivos de revisión o jurídicosbasados en dicha mensajería instantánea. No se trata de que todo pantallazo de impresión se pueda utilizar como medio de prueba, sino que se evite cualquier alteración de dicho mensaje, de ahí que ante la negativa del interesado sea preciso acudir a un perito, aunque es cierto que ello podría no ser suficiente para eliminar el

\footnotetext{
${ }^{16}$ Véase PÉREZ ASTUDILLO, N. E., «Los medios telemáticos como prueba de cargo en el proceso», Cuadernos Digitales de Formación, Consejo General del Poder Judicial, núm. 3, 2015, pág. 6.

${ }^{17}$ Véase ASOCIACIÓN DE INTERNAUTAS, ¿Se pueden manipular bajo el control de un virus troyano nuestros SMS y WhatsApp?, 6 de junio de 2013, disponible en http://seguridad.internautas.org/html/4452.html.

${ }_{18}$ De las siglas del inglés Short Message Service, esto es, servicio de mensajes cortos o servicio de mensajes simples.

${ }^{19} \mathrm{http}: / /$ www.internautas.org/.

${ }^{20}$ Cfr. MORALES VÁLLEZ, C., «La validez probatoria del whatsapp y su incorporación al procedimiento», Sepin, Madrid, 2016.
} 
riesgo de que dicha manipulación no se hubiese producido $^{21}$, pero ello ya nos introduciría en el campo de la credibilidad -si es o no posible que dicho contenido hubiese sido, en ese caso concreto, alterado-, lo que comportaría una cuestión más profunda y diferida al momento posterior a la admisión y práctica de dicha prueba (incorporación a las actuaciones) y sobre la cual no se ha pronunciado la Sentencia, si bien se mantiene un pequeño excurso -al que ya me he referido- sobre la diferencia entre la verdad formal y material, que engarza directamente con la valoración de la prueba (sana crítica). En definitiva, una resolución de práctica lectura y esclarecedora en cuanto al empleo de las redes sociales como medio de prueba en el proceso laboral.

\section{BIBLIOGRAFÍA}

ASOCIACIÓN DE INTERNAUTAS, ¿Se pueden manipular bajo el control de un virus troyano nuestros SMS y WhatsApp?, 6 de junio de 2013, disponible en http://seguridad.internautas.org/html/4452.html

GONZÁLEZ DE LA RIVERA SERRA, X., «Aplicación de la "ficta confessio" en relación con el artículo 24 de la Constitución», Aranzadi Social, núm. 6, 2002

MORALES VÁLLEZ, C., «La validez probatoria del whatsapp y su incorporación al procedimiento», Sepin, Madrid, 2016

PÉREZ ASTUDILLO, N. E., «Los medios telemáticos como prueba de cargo en el proceso», Cuadernos Digitales de Formación, Consejo General del Poder Judicial, núm. 3, 2015

VÁZQUEZ DÍAZ, X., «Modificación en suplicación de los hechos probados fuera de los estrictos cauces del art. 191 b) de la Ley de Procedimiento Laboral: en especial, el error de derecho en la valoración de la prueba y las reglas de la sana crítica», Aranzadi Social, núm. 4, 2002

\footnotetext{
${ }^{21}$ Véase ASOCIACIÓN DE INTERNAUTAS, ¿Se pueden manipular bajo el control de un virus troyano nuestros SMS y WhatsApp?, cit.
} 